$\infty$

0

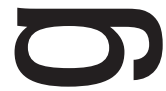

-

ת

1

$\longrightarrow$ 



\title{
IDENTIFICAÇÃO DE ILHAS DE CALOR POR MEIO DE SENSORIAMENTO REMOTO: ESTUDO DE CASO NO MUNICÍPIO DE GOIÂNIA - G0/2001
}

\author{
IDENTIFICATION OF 'HEAT ISLANDS' THROUGH REMOTE SENSING: \\ CASE STUDY IN THE CITY OF GOIÂNIA-GO, 2001 \\ IDENTIFICATION DES ÎLES DE CHALEUR PAR TÉLÉDÉTECTION: \\ ETUDE DE CAS DE LA VILLE DE GOIÂNIA EN 2001 \\ Diego Tarley Ferreira Nascimento - Universidade Federal de Goiás
diego.tarley@gmail.com \\ Juliana Ramalho Barros - Universidade Federal de Goiás \\ julianarb@superig.com.br
}

\begin{abstract}
Resumo
No presente trabalho são utilizadas técnicas de sensoriamento remoto para identificação e análise do fenômeno de ilhas de calor em Goiânia-G0, tendo como recorte temporal 0 ano de 2001. Foi utilizada a proposta metodológica de Monteiro (1976), do Sistema de Clima Urbano - SCU, em particular o subsistema Termodinâmico, visando proceder a uma análise do funcionamento, desempenho e organização do fenômeno de ilhas de calor. A elaboração do trabalho baseou-se na classificação da cobertura do solo e em um mapeamento do campo térmico do município de Goiânia, por meio das imagens das bandas 3, 4, 5 e 6 (banda termal) do Landsat 7, nas quais foram considerados como instrumentos de análise: a urbanização, as características geoecológicas (topografia) e o sistema meteorológico (clima regional). Os resultados demonstram que o fenômeno de ilha de calor é constatado no município de Goiânia, havendo diferenças de temperatura de até $10^{\circ} \mathrm{C}$ entre a área urbana e a rural do município, sendo possível caracterizar determinados usos antrópicos (classes de cobertura do solo) e intervalos altimétricos como potencializadores de maiores valores de temperatura.
\end{abstract}

Palavras-chave: Ilhas de calor. Sensoriamento remoto. Goiânia-GO.

\begin{abstract}
Techniques of remote sensing for identification and analyses of the phenomenon of heat island are used in this study for the city of Goiânia-GO, in the year of 2001. The methodology proposed by Monteiro (1976), Urban Climate System, particularly the Thermodynamic Subsystem, are used to conduct a review of operations, performance and organization of the phenomenon of heat islands. The stages of work included the classification of land cover and the mapping of thermal camp of Goiânia, through the images of bands 3, 4, 5 and 6 (thermal band) of Landsat 7 . Were considered as instruments of analysis: the urbanization, the geoecologic characteristics (topography) and the meteorology system (regional climate). The results show that the phenomenon of heat island is found in the municipality of Goiânia-G0, having differences of temperatures up to $10^{\circ} \mathrm{C}$ between urban and rural area, being possible characterize certain anthropogenic uses (land covers classes) and altimetric intervals as potentiators of higher values of temperature.
\end{abstract}

Key-words: Heat island. Remote sensing. Goiânia-G0.

\section{Résumé}

Cette étude utilise des techniques de télédétection pour l'identification et l'analyse du phénomène des îlots de chaleur dans la ville de Goiânia-G0, pour l'année 2001. La méthode proposée de Monteiro (1976), Système de Climat Urbain,

\begin{tabular}{|l|c|c|c|c|c|c|}
\hline Boletim Goiano de Geografia & Goiânia - Goiás - Brasil & v. 29 & n. 1 & p. 119-134 & jan. / jun. & 2009 \\
\hline
\end{tabular}


en particulier le sous-système Thermodynamique, a été utilisé pour procéder à un examen des activités, la performance et l'organisation du phénomène des îles de chaleur. Le travail a été basé sur la classification de la couverture du sol et d'une cartographie thermique du terrain dans la municipalité de Goiânia, par les images des bandes 3, 4, 5 et 6 (bande thermique) de Landsat 7, qui ont été considérés comme des outils d'analyse: le développement, les caractéristiques géo-ecologiques (topographie) et de système météorologique (climat régional). Les résultats montrent que le phénomène de l'îlot de chaleur se trouve dans la municipalité de Goiânia, avec des différences de température jusqu'à $10^{\circ} \mathrm{C}$ entre les zones urbaines et rurales de la municipalité, être possible de caractériser certaines utilisations anthropiques (classes de couverture des sols) et les gammes altimétriques comme potentialisateurs de température plus élevée.

Mots-clés: Îles de chaleur. Télédétection. Ville de Goiânia-GO.

\section{Introdução}

A intensa expansão demográfica que se desenvolveu nos últimos 200 anos, impulsionada pelos avanços da tecnologia agrícola, industrial e medicinal, resultou num forte processo de crescimento urbano que tem desencadeado sérios problemas ambientais. Dentre estes problemas ambientais, há a alteração do clima local - clima urbano - como um importante reflexo do impacto da ocupação e da atividade antrópica sobre o meio ambiente.

Nesse novo clima local (clima urbano), é possível constatar diferenças nos elementos climáticos, conforme a influência da cobertura do solo, no que diz respeito à alteração no fluxo de matéria e energia sobre a atmosfera local. Convém salientar que o comportamento espacial simultâneo da temperatura se revela o mais importante elemento nesse complexo sistema, tendo como principal produto o fenômeno das ilhas de calor.

Neste contexto, quando as diferenças simultâneas de temperatura ocorrem entre centro/área urbana (valores mais altos de temperatura) e periferia/área rural (valores mais baixos), denomina-se ilha de calor a delimitação desta área mais quente.

Em particular, para a execução do trabalho que resultou no presente artigo, foram utilizadas técnicas de sensoriamento remoto como suporte instrumental e metodológico para identificação e análise do fenômeno de ilhas de calor em Goiânia-GO, tendo o ano de 2001 como recorte temporal ano este selecionado considerando a pouca disponibilidade de imagens que possui o sensor empregado para o presente trabalho, o ETM+ do satélite Landsat 7, por ter sido lançado em 1999 e desativado em 2003.

Para elaboração deste trabalho, a área de estudo selecionada foi o município de Goiânia, capital do estado de Goiás (figura 1). Com uma popula- 
ção de 1.244.645 habitantes, segundo a contagem da população realizada pelo IBGE em 2007, o município destaca-se no comércio, na existência de diversas instituições de ensino superior, na prestação de serviços públicos (principalmente os de saúde), na agropecuária e na indústria.
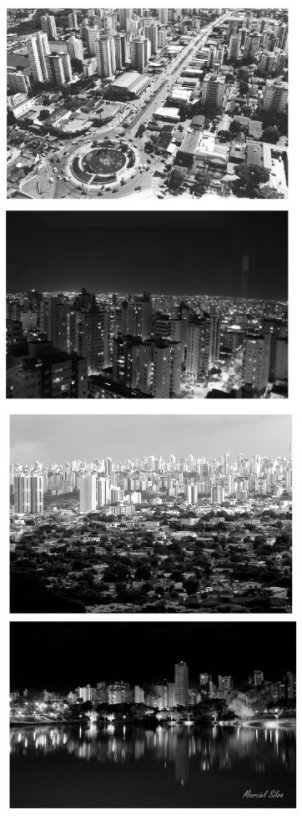

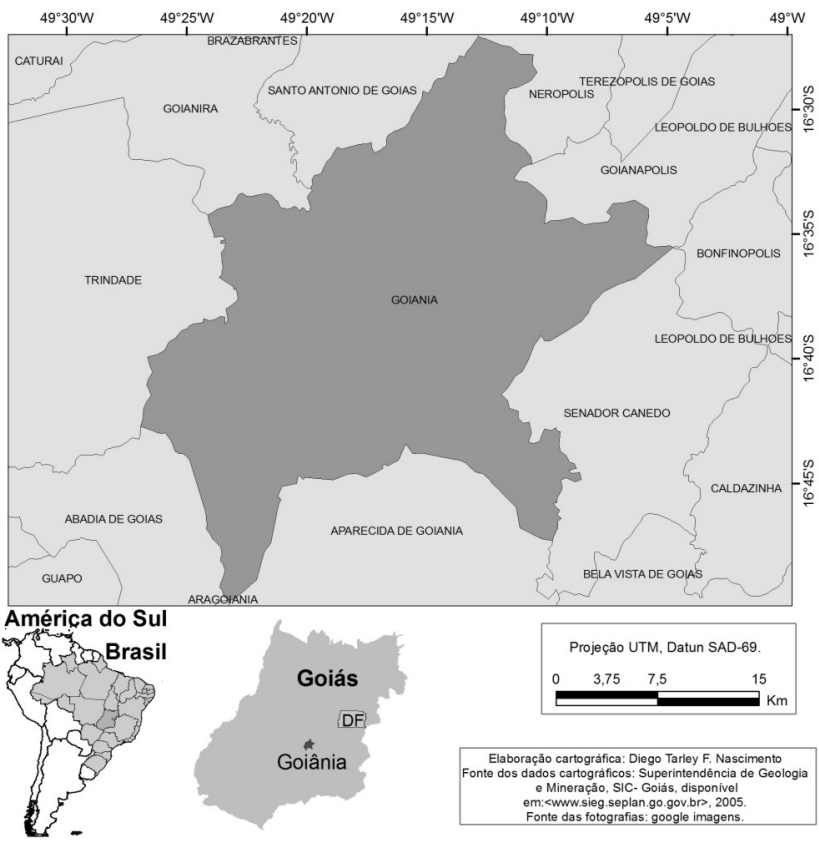

Figura 1: Mapa de localização de Goiânia-GO.

Com relação ao clima regional, observa-se a ocorrência, durante o ano, de centros de ação negativos de origem continental - massas Equatorial Continental e Tropical Continental, e centros de ação positivos individualizando-se sob a forma de massas de ar de origem marítima - massas Tropical Atlântica e Polar Atlântica, deslocando-se sobre o continente, ora avançando, ora recuando (Campos et al., 2002).

Portanto, considera-se que o clima de Goiânia é justificado pelos sistemas regionais de circulação atmosférica que atuam na região Centro-Oeste, pela sua posição latitudinal e ausência de corpos hídricos consideráveis, apresentando, por isto, um verão quente e chuvoso, uma primavera com as temperaturas mais elevadas do ano e um inverno seco com elevada amplitude térmica (NASCIMENTO; LUIZ, 2005). 


\section{O estudo do clima da cidade e de suas peculiaridades}

O estudo do clima urbano se baseia numa linha de pesquisa da climatologia responsável pela compreensão do clima da cidade, enfocando, inicialmente, uma análise espacial local (clima local) que se estende a níveis regionais (clima regional) e globais (clima zonal), destacando-se, em cada escala, a influência urbana (COLTRI, 2006).

Nesse sentido, o clima urbano pode ser definido como "um sistema que abrange o clima de um dado espaço terrestre e sua urbanização" (MONTEIRO, 1976, p. 95), sendo um sistema complexo, dinâmico, adaptativo e aberto que, recebendo energia do ambiente maior no qual se insere, a transforma substancialmente (MONTEIRO, 1976; MONTEIRO; MENDONÇA, 2003).

Em sua tese de livre docência, Monteiro (1976) desenvolveu a teoria do "Sistema de Clima Urbano - S.C.U.”, visando compreender a organização climática peculiar da cidade. Inseridos na teoria do Sistema de Clima Urbano, encontram-se três subsistemas que se articulam e se integram, a saber: o Termodinâmico no tocante ao conforto térmico; o Hidrodinâmico, no que tange ao impacto meteórico (chuvas intensas); e o Físico-Químico, que diz respeito à qualidade do ar. Dentre esses subsistemas, destaca-se aqui o Termodinâmico, que, segundo Monteiro (1976, p. 126), caracteriza-se como o "nível fundamental de resolução climática para onde convergem e se associam todas as outras componentes". Este subsistema apresenta um desenvolvimento contínuo e possui, como principal produto, as ilhas de calor.

\section{0 fenômeno de ilhas de calor}

A ilha de calor resulta do processo de crescimento urbano, a partir da alteração da superfície e da atmosfera local por conta da modificação da cobertura do solo - construção de casas, edifícios, impermeabilização do solo (asfalto e concreto), retirada da cobertura vegetal e das próprias atividades antrópicas, favorecendo a absorção do fluxo radiante solar (CAMARGO et al., 2007) que propicia um aumento significativo da "irradiação de calor para a atmosfera em comparação com as zonas periféricas ou rurais”, onde não é visto um processo de ocupação tão intenso em comparação ao centro da cidade (TEZA; BAPTISTA, 2005, p. 3911).

Consideram-se como causas para a existência de ilhas de calor dois elementos: a condição da superfície e os controladores atmosféricos (OKE, 
1982 apud GARCIA-CUETO et al., 2007). O primeiro elemento se traduz na cobertura do solo, na topografia do sítio, na estrutura urbana e nas funções e atividades antrópicas, enquanto o segundo diz respeito à influência das nuvens e dos ventos (direção e intensidade) na condição da estrutura térmica da superfície.

Não obstante, vários são os métodos de investigação das ilhas de calor. A utilização de dados provenientes de estações meteorológicas oficiais (a exemplo, do Instituto Nacional de Meteorologia - INMET) e a coleta local de dados de temperatura do ar em mini-abrigos termométricos são os métodos mais indicados pela confiabilidade do valor real dos dados. Porém, sua espacialização não apresenta a adequação quanto à compreensão do fenômeno, visto que a representação dos valores de temperatura do ar em isolinhas não informa a real extensão dos valores, mas sim a extensão da variação entre aqueles coletados, resultando assim, numa forte generalização (MONTEIRO; MENDONÇA, 2003). Uma imensa dificuldade neste método é a quantidade de pontos de coleta de dados, bem como a sua espacialização (por exemplo, centro-periferia, norte/sul).

Nesse contexto, a partir da década de 1970 o sensoriamento remoto passou a ser bastante empregado nos estudos de ilhas de calor, sendo possível,

[...] além das visões em diferentes escalas, realizar medidas através dos dados do sensor infravermelho termal em temperatura aparente da superfície (land surface temperature - LST), fornecendo a temperatura qualitativa da cidade, ou seja, o desenho da temperatura local (COLTRI et al., 2007, p. 5151).

Ao considerar a Lei de Plank, segundo a qual "quanto maior a temperatura de um dado comportamento de onda, maior será a quantidade de energia emitida por um corpo negro” (BIAS; BAPTISTA; LOMBARDO, 2003, p. 1742), e ponderar a capacidade dos sensores dos satélites em detectar a radiação em ondas longas emitida na faixa do infravermelho termal - considerada termal por ser nesta faixa que é detectada a radiação emitida pelos objetos, que varia em função de sua temperatura (STEINKE; STEINKE; SAITO, 2004) -, pode ser possível levantar a temperatura de determinado local ou objeto por meio da transformação dos tons de cinza das imagens termais em valores de temperatura aparente da superfície, baseando-se, para isso, na aplicação de um algoritmo.

É oportuno enfatizar que a temperatura do ar (Tar) e a temperatura da superfície terrestre (TST - mensurados pelos sensores orbitais) são ele- 
mentos distintos. Todavia, elas possuem relação íntima, haja vista o conhecimento das relações que possam ser estabelecidas entre elas, conceitualmente ou por meio de parametrizações (COLTRI et al., 2007), justificando a aplicação deste método nos estudos de ilhas de calor.

\section{Metodologia}

A elaboração do trabalho consistiu no tratamento das imagens do sensor ETM+ do satélite Landsat 7, de orbita/pontos 221-71 e 72 (referente às bandas $3,4,5$ e 6), que consistiu na classificação da cobertura do solo no qual foi empregado o algoritmo da máxima verossimilhança (Maxver) e propostas quatro classes de cobertura do solo: cobertura vegetal; corpos hídricos; agropecuária; e área urbana. O trabalho buscou também e no mapeamento do campo térmico do município - o qual consistiu na transformação dos níveis de cinza das imagens em valores de temperatura em graus centígrados por meio do "módulo thermal”, existente no IDRISI.

Para tanto foram utilizados os software ENVI 4.3, IDRISI: The Andes Version 15.00 e o ArcGIS 9.2, sendo o primeiro software utilizado para classificação da cobertura do solo, o segundo para o mapeamento do campo térmico, e o último para finalização dos mapas.

Foi empregada como base metodológica a proposta de Monteiro (1976) do Sistema de Clima Urbano (SCU) para a análise dos mecanismos, compreensão do processo de formação e análise do fenômeno de ilhas de calor, sendo considerados como instrumentos de análise: 1) a urbanização, no tocante à morfologia/função urbana; 2) as características geoecológicas, considerando a topografia - por ser o elemento geoecológico de maior influência no comportamento espacial da temperatura; 3) o sistema meteorológico (clima regional).

\section{Caracterização da ilha de calor no município de Goiânia}

De acordo com o mapa de Temperatura Aparente da Superfície do município de Goiânia-GO/2001 (figura 2), constatam-se nas áreas periféricas valores aparentes de temperatura variando entre 24 e $26^{\circ} \mathrm{C}$, havendo inclusive áreas com valores alcançando os $22^{\circ} \mathrm{C}$. Em contrapartida, as áreas centrais apresentam valores entre 26 e $28^{\circ} \mathrm{C}$ e, nas mais centralizadas (urba- 
nizadas), valores de temperatura atingindo os $32^{\circ} \mathrm{C}$. Havendo, portanto, uma variação de até $10^{\circ} \mathrm{C}$ entre a área urbana e rural do município de Goiânia.

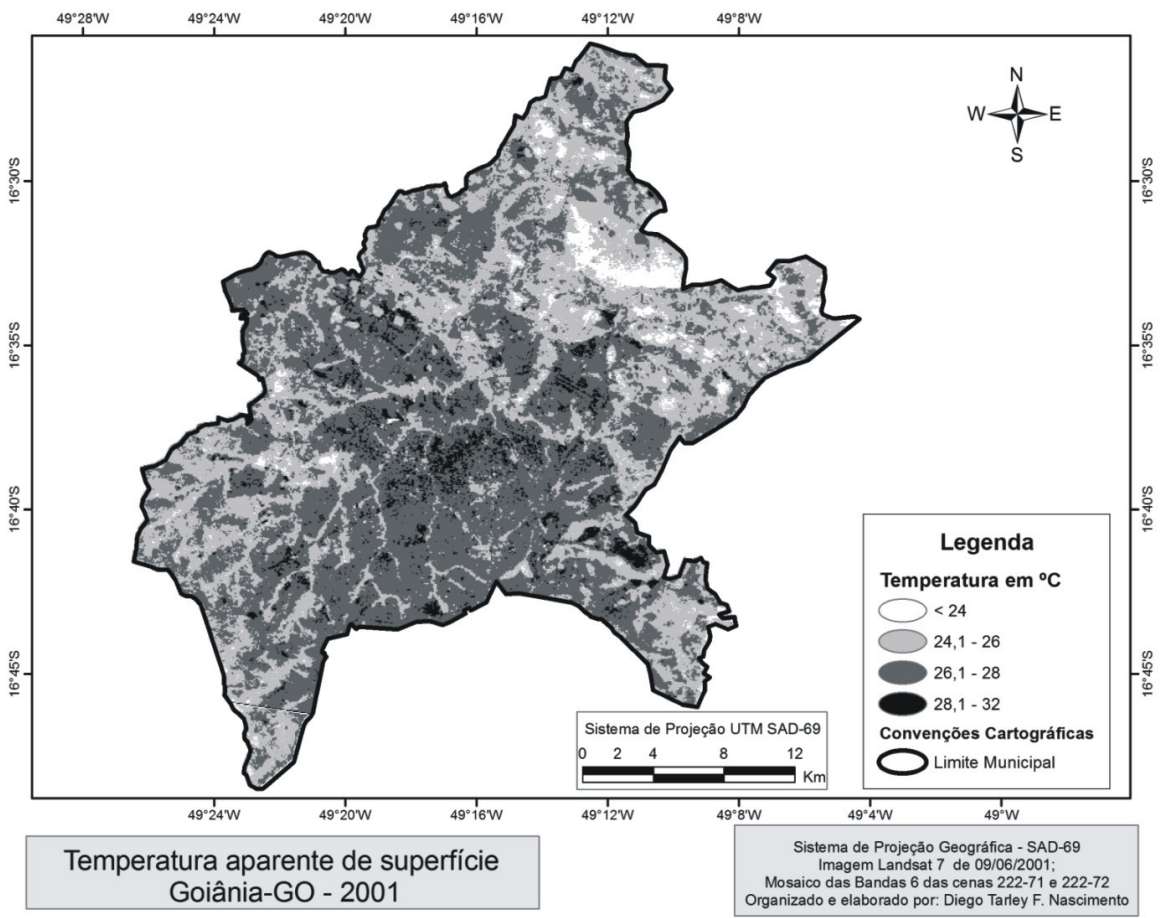

Figura 2: Mapa de Temperatura Aparente de Superfície do município de Goiânia-GO/2001

É possível verificar que os valores mais altos de temperatura encontram-se na área urbana, ao passo que os menores encontram-se nas áreas rurais. Ressalta-se que dentre as áreas rurais, aquelas localizadas na porção nordeste, são as que possuem os menores valores de temperatura aparente, ou seja, valores abaixo dos $26^{\circ} \mathrm{C}$.

Já na área urbana, percebe-se o predomínio de temperaturas aparentes na classe dos 26,1 a $28^{\circ} \mathrm{C}$ e, em alguns locais, valores mais elevados, alcançando os $32^{\circ} \mathrm{C}$. É importante ressaltar a mancha relativamente contínua de valores mais elevados de temperatura aparente $\left(28\right.$ a $\left.32^{\circ} \mathrm{C}\right)$ que ocorre na porção central do município, com início a oeste, nos Setores São José e Rodoviário, intensificado-se nos setores Campinas, Coimbra e 
Centro Oeste, limitada a norte pelo setor Criméia Oeste, ao sul pelo setor Central e dos Funcionários, e a leste pelos setores Leste Vila Nova e Negrão de Lima (figura 3).

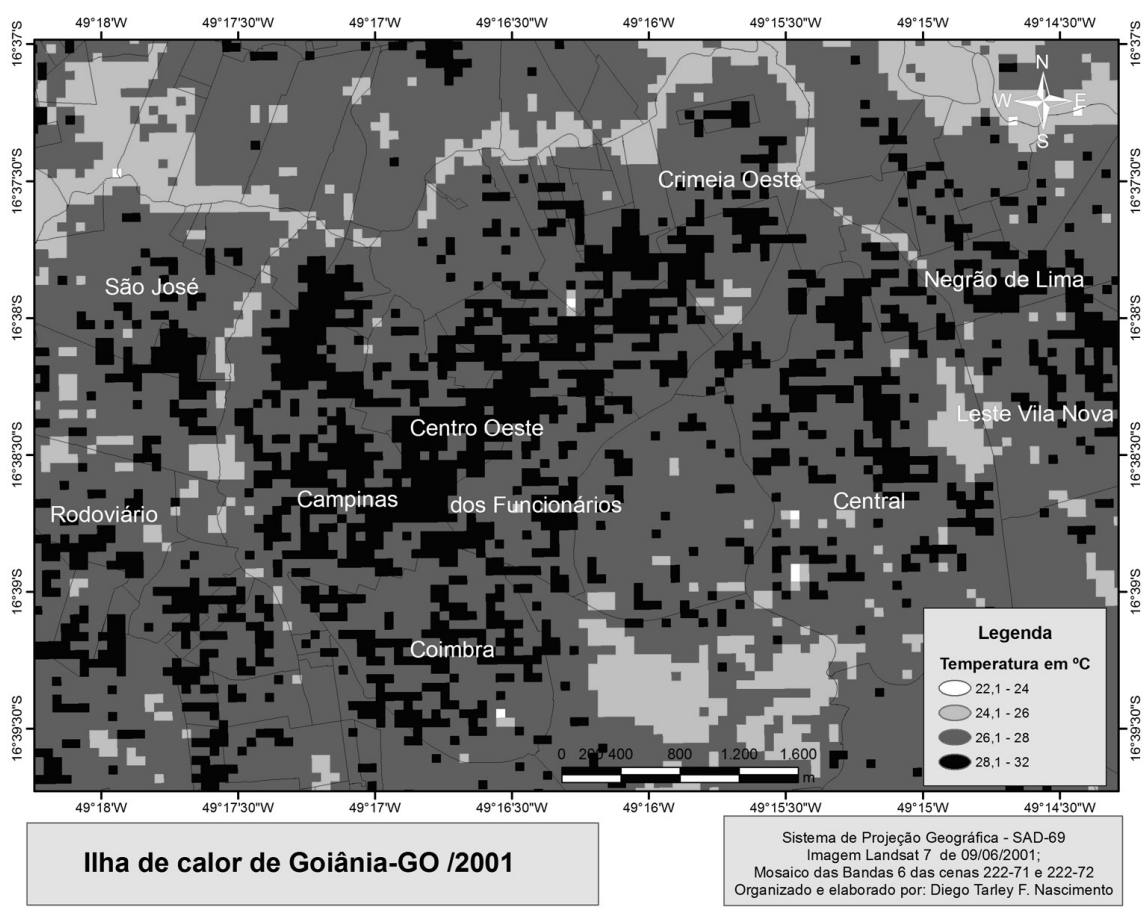

Figura 3: Ilha de calor na região central da Macrozona Construída.

Considerando a resolução da imagem termal utilizada do Landsat 7 (60 metros), mesmo com essa fragmentação dos valores mais elevados de temperatura, pode-se presumir que esta seja uma área de ilha de calor, isto devido à continuidade dos locais com estes valores mais elevados de temperatura.

Estes valores mais altos de temperatura decorrem do fato de em tais locais haver um uso urbano mais intenso, haja vista que os setores Central, Campinas, Centro-Oeste e Coimbra se destacam pela intensa edificação, pavimentação asfáltica e atividade comercial ali existente, como também pela pouca presença de corpos hídricos e áreas verdes. E, de fato, esses elementos corroboram para a existência dos valores elevados de temperatura. 


\section{Correlação da cobertura do solo ao campo térmico do município de Goiânia}

Considerando a relação do uso e cobertura do solo existente com os valores de temperatura, é importante frisar que o uso urbano (principalmente o mais central/concentrado) é um importante elemento para caracterizar a ilha de calor, isto porque o uso irá especificar o grau de urbanização e atividades antrópicas passíveis de ali existirem. A figura 4 apresenta a relação do uso urbano (uso rural, comercial, central, residencial urbano e suburbano) ao perfil dos valores de temperatura aparente da superfície, onde é plausível compreender que nas áreas mais centrais, e por conseguinte, mais urbanizadas, os valores de temperatura tendem a ser os mais elevados, como ocorre nos locais com atividades comerciais, devido a pouca existência de cobertura vegetal ou corpos hídricos. Em contrapartida, locais com uso residencial urbano e suburbano, como também uso rural, tendem a apresentar os menores valores de temperatura.

\section{Perfil da Ilha de calor em Goiânia-GO/2001}

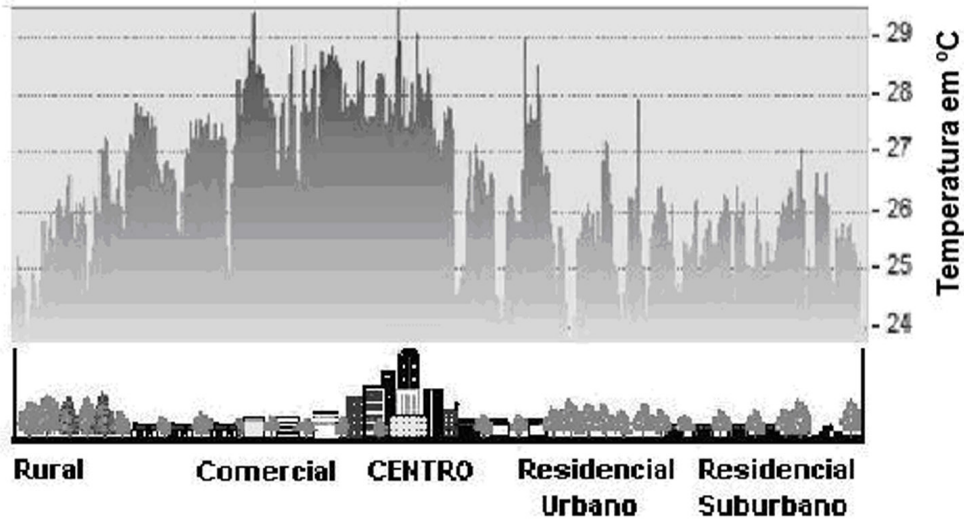

Figura 4: Perfil de Ilha de Calor em Goiânia-GO/2001. Fonte: elaborado pelo autor.

É possível, conforme relata a literatura sobre o assunto em questão, correlacionar também os corpos hídricos e as áreas verdes aos valores mais baixos de temperatura, assim como o contrário, quando de sua inexistência. Nesse sentido, a análise da cobertura do solo pode colaborar na caracterização das ilhas de calor.

De acordo com a figura 5, as áreas urbanas (mais antropizadas) se encontram na porção centro-sul, decorrente do processo de conurbação que 
o município sofre em seu setor meridional com a porção setentrional do município de Aparecida de Goiânia. Nas últimas décadas (1975 a 2002), a área urbana (originalmente central) teve como principais vetores de crescimento as direções oeste e norte (SILVA; FERREIRA; BOGGIONE, 2005), seguidas pela porção leste e, por último, sul. Nessas últimas duas áreas prevalecem os valores de temperatura compreendidos entre 26,1 e $28^{\circ} \mathrm{C}$, e em alguns locais alcançando os $32^{\circ} \mathrm{C}$.

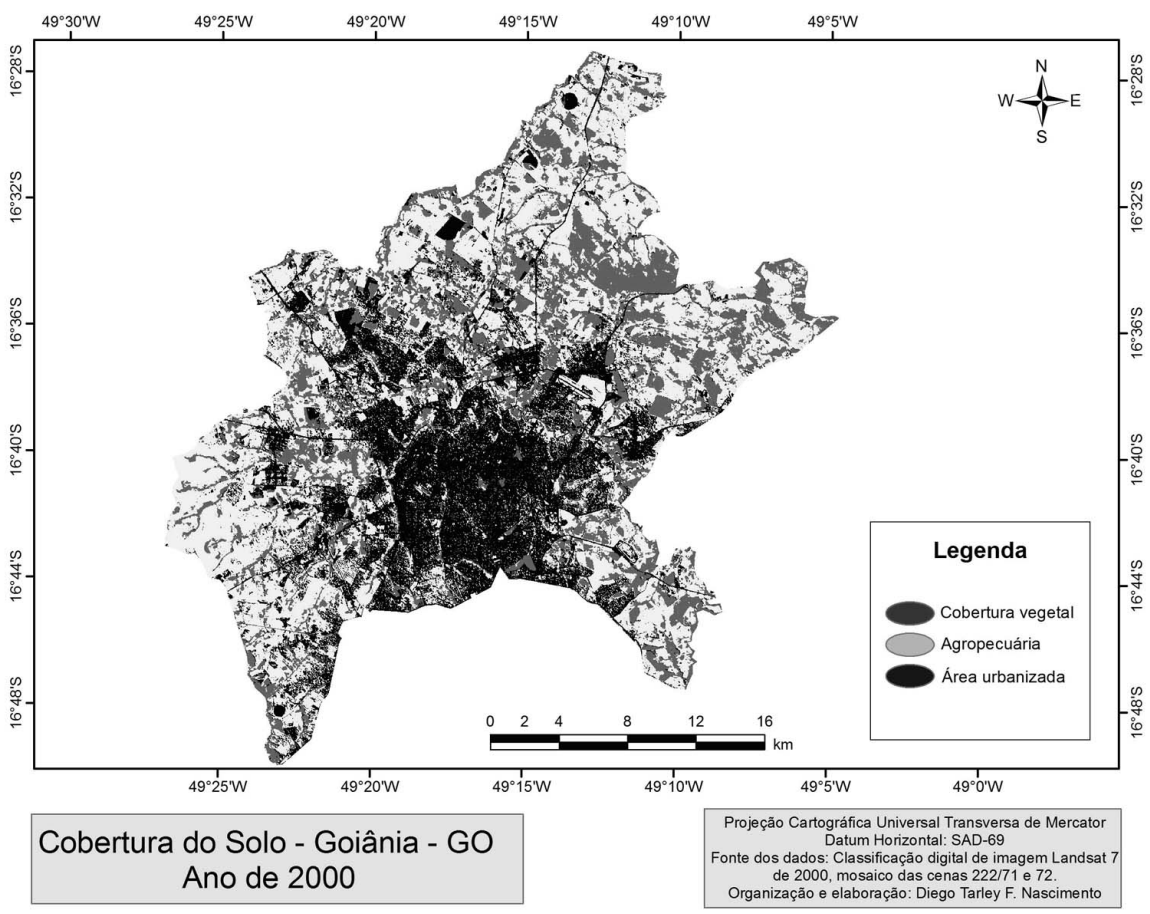

Figura 5: Mapa de Cobertura do solo - Município de Goiânia-GO/2000.

O uso agropecuário prevalece nas zonas rurais do município, localizadas nas áreas periféricas, com maior ênfase nas porções norte e nordeste, condicionando valores médios de temperatura da ordem de 24 a $26^{\circ} \mathrm{C}$.

As áreas com remanescentes de vegetação (cobertura vegetal) destacam-se nas porções norte, nordeste e sudeste, havendo ainda pequena quantidade na porção oeste - principalmente acompanhando os corpos hídricos (matas de galeria). É neste tipo de cobertura do solo onde são encontrados os 
menores valores de temperatura, além de observados, de modo geral, valores abaixo de $22^{\circ} \mathrm{C}$ e, em alguns pontos, temperaturas de até $26^{\circ} \mathrm{C}$.

Duarte e Serra (2003) ressaltam o papel das áreas verdes e das superfícies d' água no conforto higrotérmico e na qualidade do ar, e consideram que quando elas se encontram melhor distribuídas pela cidade (mesmo sendo pequenas áreas, pequenos parques) influenciam mais nos elementos supracitados. Nessa mesma linha de raciocínio, Camargo et al. (2007) afirmam que a presença de cobertura vegetal e hídrica favorece a absorção do fluxo radiante solar, com consequente redução do calor sensível e da temperatura.

Nesse sentido, convém frisar que o município de Goiânia recentemente recebeu o título de cidade que tem mais áreas verdes por habitante (AMMA, 2007). A Agência Municipal de Meio Ambiente estima que Goiânia possua $94 \mathrm{~m}^{2}$ de áreas verdes por habitante, superando Curitiba $\left(53 \mathrm{~m}^{2} /\right.$ hab.), referência em áreas verdes no Brasil, e outros municípios - Belo Horizonte (30 m²/hab.) e João Pessoa (18 $\mathrm{m}^{2} / \mathrm{hab}$.).

Não obstante, a figura 2 revelou o papel dos corpos hídricos como atenuadores dos valores de temperatura, haja vista a existência de uma zona de alívio térmico de aproximadamente 500 metros sobre as drenagens, de acordo com a largura dos cursos d'água. O Rio Meia Ponte, principal manancial de Goiânia, que atravessa o município no sentido noroeste-sudeste, destaca-se por amenizar os valores de temperatura principalmente da região central e centro-norte.

\title{
Influência da topografia no campo térmico do município de Goiânia
}

\author{
Segundo Duarte e Serra (2003, p. 12):
}

O fato da zona urbana [de Goiânia] estar situada em uma depressão geográfica faz com que a freqüência e a velocidade média dos ventos seja extremamente baixa, minimizando o efeito das trocas térmicas por convecção e ressaltando ainda mais a influência do espaço construído sobre a temperatura do ar.

Portanto, uma análise que contemple as características topográficas do município é de suma importância, uma vez que esse elemento poder influenciar enormemente as condições da temperatura do ar e, consequentemente, das ilhas de calor.

A figura 6 apresenta um perfil topográfico associado ao perfil de temperatura, o que possibilita a percepção de uma correlação negativa entre a 
topografia e os valores de temperatura, demonstrando que é possível relacionar os locais menos elevados aos maiores valores de temperatura, e assim, caracterizar tais regiões como sendo propícias a sofrerem com maior intensidade o fenômeno de ilhas de calor.

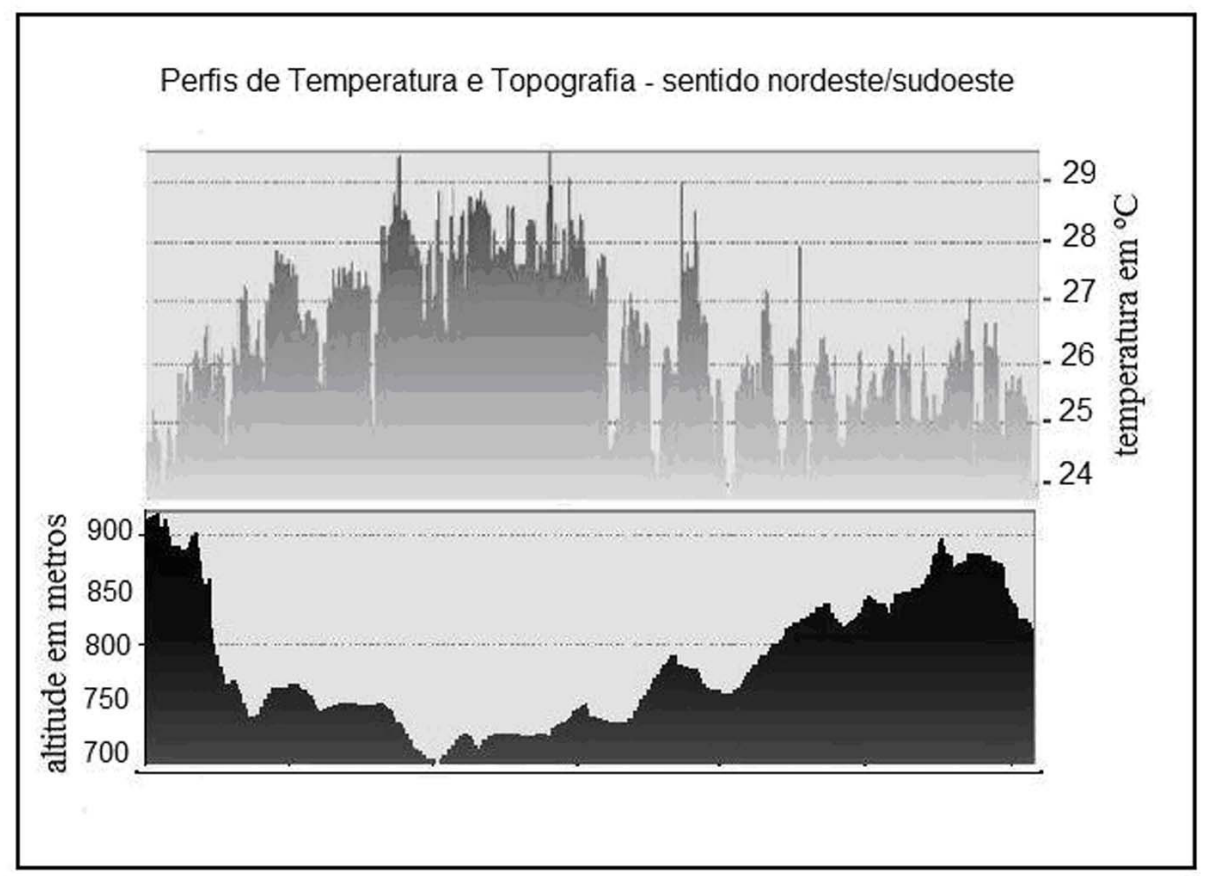

Figura 6: Perfis de temperatura e topografia de Goiânia, sentido NE-SW. Fonte: elaborado pelo autor.

Neste sentido, comparando visualmente o mapa de Hipsometria de Goiânia e o mapa de Temperatura Aparente de Superfície (figura 7), é possível perceber que os maiores valores de temperatura encontram-se na planície fluvial do Meia Ponte e também nos fundos de vale de seus tributários (que variam dos $659 \mathrm{~m}$ aos $760 \mathrm{~m}$ ). Não obstante, o contrário (menores valores) se dá em áreas com maiores valores altimétricos (800 m aos $960 \mathrm{~m}$ ), como é o caso das porções norte e nordeste do município. 

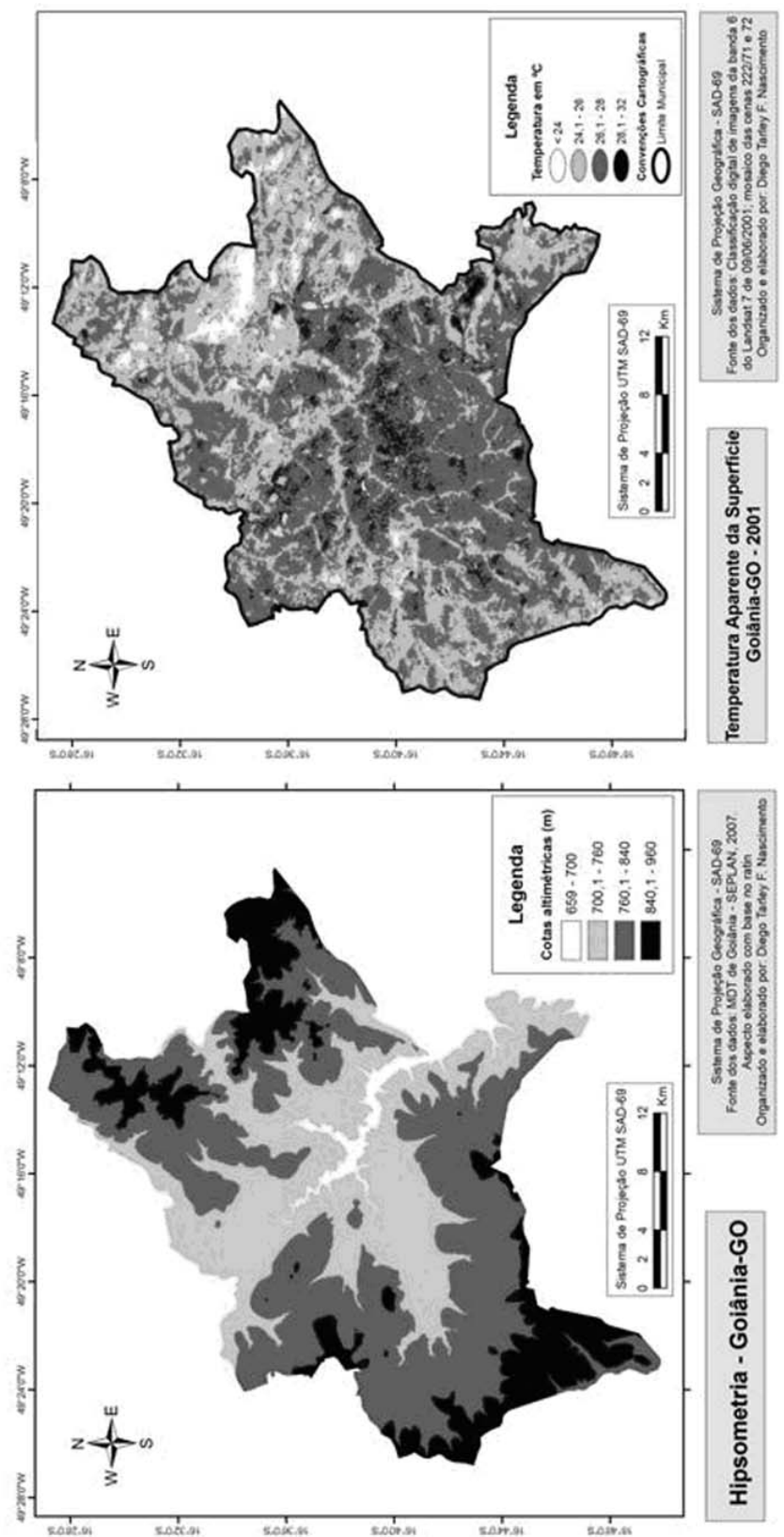
As representações cartográficas apresentadas e analisadas corroboram a ideia da existência do fenômeno de ilhas de calor no município de Goiânia. Entretanto, cabe lembrar que a data de elaboração dos produtos cartográficos é o ano de 2001 e que, por isso, é possível que tal fenômeno tenha ainda se intensificado conforme se desenvolveu a ocupação antrópica e a conversão de coberturas naturais por antropizadas no município, ao longo dos anos seguintes.

\section{Considerações finais}

Goiânia, apesar de ser uma cidade relativamente nova e resultar de uma proposta de plano urbanístico, já apresenta sérios problemas advindos da ocupação antrópica. Entre muitos outros fenômenos, o das ilhas de calor já é constatado, sendo possível mensurar diferenças significativas de temperatura entre as áreas urbana e rural do município.

É possível caracterizar determinados usos antrópicos (cobertura do solo) e intervalos altimétricos como potencializadores de maiores valores de temperatura. Como exemplo, as classes de cobertura do solo urbano - por apresentar maior proporção de revestimento asfáltico da superfície, maior densidade de construções e atividades antrópicas, e ainda, um enorme fluxo de veículos no centro da cidade - e agropecuária, em oposição aos de cobertura vegetal e corpos hídricos, e ainda, altitudes mais elevadas com menores valores de temperatura que regiões mais elevadas. Neste sentido, ressalta-se o forte papel dos corpos hídricos e cobertura vegetal, além de locais mais elevados, como aliviadores térmicos.

Enquanto em locais adjacentes a áreas verdes e corpos hídricos verificam-se valores de temperatura menores que $22^{\circ} \mathrm{C}$, podendo, em alguns pontos, ocorrer o valor máximo de $26^{\circ} \mathrm{C}$, em outros locais (região central), com intensa quantidade de construções e fluxo de atividades antrópicas, as temperaturas podem alcançar os $32^{\circ} \mathrm{C}$.

Dentre as diversas técnicas de se investigar um fenômeno como o de ilhas de calor (coleta de dados de estações ou de postos móveis, instrumentos meteorológicos etc.), o sensoriamento remoto se justifica pela melhor distribuição espacial dos dados, haja vista que é possível levantar o desenho térmico da área em estudo, tendo condição de analisar a variação espacial simultânea da temperatura, considerando a rugosidade, as construções e os usos existentes.

Possibilidades de trabalhos futuros que contemplem tal investigação em uma análise em série histórica seriam bastante oportunos, haja vista que 
o fenômeno poderia ser compreendido em seu processo de formação/evolução. Como também estudos que empreguem imagens de alta resolução espacial, como exemplo das imagens do sensor ASTER (Advanced Spaceborne Thermal Emission and Reflection Radiometer), a bordo do satélite TERRA, com resolução de 15 metros, capaz de apresentar maior gama de dados a serem trabalhados.

\section{Referências}

BIAS, E. de S.; BAPTISTA, G. M. de M.; LOMBARDO, M. A. Analise do fenômeno de ilhas de calor urbanas, por meio da combinação de dados Landsat e Ikonos. In: SIMPÓSIO BRASILEIRO DE SENSORIAMENTO REMOTO, 11., 2003, Belo Horizonte. Anais XI SBSR, Belo Horizonte, 2003. p. 1741-1748.

CAMARGO, F. F. et al. Análise multitemporal da evolução urbana e sua influência na modificação do campo térmico na Região Metropolitana de São Paulo para os anos de 1985, 1993 e 2003. SIMPÓSIO BRASILEIRO DE SENSORIAMENTO REMOTO, 13, Florianópolis. Anais do XIII SBSR, Florianópolis, 2007. p. 5127-5134.

COLTRI, P. P. Influência do uso e cobertura do solo no clima de Piracicaba, São Paulo: analise de séries históricas, ilhas de calor e técnicas de sensoriamento remoto. 2006. Dissertação (Mestrado em Fitotecnia) - Escola Superior de Agricultura Luiz de Queiroz.

COLTRI, P. P. et al. Ilhas de calor da estação de inverno da área urbana do município de Piracicaba, SP. Simpósio brasileiro de sensoriamento remoto, 13, Florianópolis. Anais do XIII SBSR, Florianópolis, 2007. p. 5151-5157.

DUARTE, D. H. S.; SERRA, G. G. Padrões de ocupação do solo e microclimas urbanos na região de clima tropical continental brasileira: correlações e proposta de um indicador. Ambiente Construído, Porto Alegre, v. 3, n. 2, p. 7-20, abr./jun. 2003.

GARCIA-CUETO, R. et al. Detection of the urban heat island in Mexicali, B. C., Mexico and it relationship with land use. Atmosfera, abril, ano/v. 20. Universidad Nacional Autônoma de México. Distrito Federal, México. 2007, p. 111 -131.

MONTEIRO, C. A. F. Teoria e clima urbano. São Paulo: IGEOG/USP, 1976. 181 p. (Série Teses e Monografias, 25).

MONTEIRO, C. A. F.; MENDONÇA, F. Clima urbano. São Paulo: Contexto, 2003. 192 p.

NASCIMENTO, D. T. F.; LUIZ, G. C. Levantamento do comportamento da mínima e máxima temperatura do ar em Goiânia-GO - 2000/2006. In: SIMPÓSIO BRASILEIRO DE GEOGRAFIA FÍSICA APLICADA. 12., Natal, jul. 2007. Anais do XII SBGFA. Natal, UFRN. 1 CD-ROM.

NIMER, E. Climatologia do Brasil. Rio de Janeiro: IBGE, 1989. 422p. 2ed.

SILVA,W. V. da; FERREIRA, N. C. BOGGIONE, G. de A. Análise de vetores de crescimento para a quantificação das transformações urbanas no município de Goiânia. SIMPÓSIO BRASILEIRO DE SENSORIAMENTO REMOTO, 12, Goiânia. Anais do XII SBSR, Goiânia, 2005. p. 681-688. 
STEINKE, E. T.; STEINKE, V. A.; SAITO, C. H. Avaliação da estimativa da temperatura de superfície a partir de imagens de satélite Landsat TM 5 voltada para a gestão de bacias hidrográficas. In: SAITO, C. H. (org.). Desenvolvimento tecnológico e metodológico para mediação entre usuários e comitês de bacia hidrográfica. Brasília: Departamento de Ecologia da Universidade de Brasília, 2004. p. 41-64.

TEZA, C. T. V.; BAPTISTA, G. M. de M. Identificação do fenômeno ilhas urbanas de calor por meio de dados ASTER on demand 08 - Kinetic Temperature (III): metrópoles brasileiras. SIMPOSIO BRASILEIRO DE SENSORIAMENTO REMOTO, 12. Goiânia, 2005. Anais do XII SBSR. p. 3911-3918.

Diego Tarley Ferreira Nascimento - Mestrando do Programa de Pesquisa e Pós-graduação em Geografia do Instituto de Estudos Socioambientais da Universidade Federal de Goiás.

Juliana Ramalho Barros - Doutora em Geografia/UNESP- Rio Claro e Professora do Instituto de Estudos Socioambientais da Universidade Federal de Goiás.

Recebido para publicação em Janeiro de 2009 Aceito para publicação em Maio de 2009 